\title{
Morphometric sex determination of Great Grey Owls
}

\section{Strix nebulosa}

\author{
Risto Tornberg ${ }^{1 *}$, Heimo Mikkola ${ }^{2} \&$ Seppo Rytkönen ${ }^{1}$ \\ ${ }^{1}$ University of Oulu, P.O.B. 3000, FIN-90014, Oulu, Finland \\ ${ }^{2}$ University of Eastern Finland, P.O.B. 1625, FIN-70211 Kuopio, Finland \\ "Correspondence: ristotorn@gmail.com
}

\begin{abstract}
Suggestions have been made for sexing Great Grey Owls Strix nebulosa using body measurements as criterion. Here we present measurement data from a long-term collection of 83 dead owls from western and northern Finland indicating that lengths of forearm, and claws 1,2 and 4, are superior over traditional measurements of wing, tarsus, bill and body mass in determining sex of Great Grey Owls. Forearm of males ranged 123-148 mm, and was on average $138 \mathrm{~mm}(\mathrm{n}=31)$. In comparison, the forearm of females ranged 131-162 mm, with an average of 147 $\mathrm{mm}(\mathrm{n}=49)$. Based on a logistic regression analysis, the combination of forearm, second claw and wing length was the best predictor in correct sex determination of $95 \%$ of the Great Grey Owl specimens.
\end{abstract}

Keywords: sex determination; owl morphometrics; ROC-curve

\section{INTRODUCTION}

Sex determination is an important part of ringing and studying birds, and is often based on plumage dimorphism. Unfortunately, many owl species show no such sexual dimorphism. Although Snowy Owl Bubo scandiacus, Barn Owl Tyto alba, Short-eared Owl Asio flammeus and Northern Long-eared Owl Asio otus show differences in colour patterns between sexes (Mikkola \& Lamminmäki 2014), other species, such as the Great Grey Owl Strix nebulosa, do not. So to date there appears to be no fully reliable non-internal method for determining sex in the Great Grey Owl. Sexing of breeding owls is easy, because usually only the female has distinct brood patches. However, in some owl species, like Barn Owls, males may show small brood patches as well (Mikkola 2013). Sexing owls outside the breeding season, however, when the females do not have brood patches, would take into account that owls show reversed size dimorphism (RSD), with females being larger than males (e.g. Martínez et al. 2002, Delgado \& Penteriani 2004). Recently, (Delgado \& Penteriani 2004) presented a method for sexing the world's largest owl, the European Eagle Owl Bubo bubo, which shows minimal outer sexual dimorphism in plumage.

Due to its late southward expansion, especially in Norway and East Central Europe, the Great Grey Owl has been the subject of increasing research in the last few years (Solheim 2009, Berg 2010, Ławicki et al. 2013). Mass movements during the winter months have increased the ringing of mouse-lured and trapped Great Grey Owls in Europe and also in North America
(Stefansson 1997, Nero 1980). For this reason, a method for practical field level sexing would represent a much-needed tool in future studies when examining intra- and intersexual patterns. Here we present results from a study of museum specimens to explore how and to what extent morphometric measurements can be used for sexing the Great Grey Owls in the field.

\section{MATERIAL AND METHODS}

Our material is from the University of Oulu, Finland, and consists of 83 measurable skin samples of Great Grey Owl specimens found dead in western and northern Finland during 1962-2004.

Numerous measurements have been taken from each owl before preparation for museum samples. These are body length from tip of the bill to base of the tail, length of flattened and rectified wing cord, length of tail, tarsus and bill, and total length of the bird from bill to end of the tail. In addition to these standard measurements, we measured length of forearm from elbow to wrist, height of bill, and length of claws. We also measured length of bill (culmen) from tip of the bill to the skull. During the preparation, the owls were sexed based on gonadal shape, and length of testicles and ovary was measured in most cases. Owls were assigned to yearlings or adults based on colouration of the tip of the wing feathers. Juveniles have an extra narrow band after the last main stripe of the feather, while adults lack this feature (Suopajärvi \& Suopajärvi 1994). Adults were more frequent among the females $(57 \%)$ than among the males $(42 \%)$ in our sample. 
We first compared the above-mentioned characters of all 83 skins by t-test to select the best ones for further analysis, because not all could be fitted to the logistic regression models we used for finding out the particular measurement or combination of measurements best explaining sex of the Great Grey Owl (see Delgado \& Penteriani 2004). Two reasons for that were: 1) our sample size did not allow for more than six variables to be modelled at one time, and 2) some variables had missing values. Due to the latter, the final sample size decreased to 76 owl specimens, out of which 29 were males and 47 were females. We used general linear model function with binomial distribution for the response variable (male $=0$ and female $=1$ ) of stats package in Program R (version 3.3.3). We considered logistic regression better than the traditional discriminate function analysis (DFA), since logistic regression is more robust for multi-normal requirements compared to DFA (see Press \& Wilson 1978). However, both methods are equally valid for sex determination.

We used Akaike Information Criteria (AIC) for model selection. AIC optimizes between complexity and precision among the competing models, and the one with the lowest AIC value is considered the best. However, models with AIC value differing $<2$ from the best are considered to be competing, and among these the one with fewest parameters is considered the most parsimonious model (Burnham \& Anderson 2002).

Models were cross-validated by ROC-curve estimation in R using AUC-function of cvAUC -package (Robin et al. 2015). First, the sample (76 owls) was randomly divided into five groups, in each of which the owls were sexed by the model obtained from the rest of the data (leave-one group-out method). This process was repeated 100 times, and the results were compared with the known sex of the individuals. True positive (correctly predicted) and false positive samples (falsely predicted) in $\mathrm{x}-\mathrm{y}$ coordinates give the so-called ROC-curve, which simply means an area below ROCcurve formed by true positive-false positive pairs and diagonal from lower left corner and upper right corner of the diagram. Coordinate pairs close to the upper left corner indicate excellent discrimination of the sexes. The area limited by the ROC-curve and the diagonal is comparable to accuracy of the model by which the sex was determined.

\section{RESULTS AND DISCUSSION}

There was a clear size difference between female and male Great Grey Owls, but the weight or wing measurements alone were not enough for sexing them reliably (Table 1). Most characters have a marked size overlap.

Applying logistic regression in predicting sex of Great Grey Owls showed that the best model included age, length of forearm, wing length, and length of the second claw (Table 2, Figure 1). However, two other models were within delta $\mathrm{AIC}<2$, proving for almost equal discrimination of the sex. Removing or adding variables did not improve the accuracy of the model. AIC values also increased in both cases. Unexpectedly, the model with lowest Akaike value did not perform best in ROC-curve estimation, predicting sex correctly in $92.5 \%$ of cases ( $\mathrm{CI}=85.8-99.1$ ) while the third model predicted sex correctly in $95 \%$ of the cases $(95 \%$

Table 1. Results from skin measurements (linear measurements in mm; weight in g) of 83 Finnish Great Grey Owl specimens, with t-tests of the difference between the sexes. The data were collected in western and northern Finland during 1962-2004.

\begin{tabular}{|c|c|c|c|c|c|c|c|c|c|c|}
\hline & \multicolumn{4}{|c|}{ Females } & \multicolumn{4}{|c|}{ Males } & \multirow[b]{2}{*}{$\mathrm{t}$} & \multirow[b]{2}{*}{$\mathrm{p}$} \\
\hline & mean & range & SE & $\mathrm{n}$ & mean & range & SE & $\mathrm{n}$ & & \\
\hline Forearm & 147 & $131-162$ & 0.7 & 49 & 138 & $123-148$ & 0.9 & 31 & 8.23 & $<0.001$ \\
\hline Claw 1 & 27.5 & $23.3-30.6$ & 0.2 & 50 & 24.8 & $21.3-27.5$ & 0.3 & 33 & 7.91 & $<0.001$ \\
\hline Claw 2 & 26.4 & $22.4-29.0$ & 0.2 & 50 & 23.6 & $19.5-26-7$ & 0.3 & 33 & 7.54 & $<0.001$ \\
\hline Claw 4 & 25.0 & $22.3-27.0$ & 0.2 & 49 & 22,7 & $19.1-25.7$ & 0.3 & 33 & 7.23 & $<0.001$ \\
\hline Weight & 1065 & $680-1489$ & 30.0 & 49 & 776 & 503-1331 & 33.7 & 32 & 6.33 & $<0.001$ \\
\hline Wing & 457 & $374-491$ & 2.4 & 50 & 437 & $404-456$ & 2.3 & 31 & 6.00 & $<0.001$ \\
\hline Bill length & 43.0 & $40.1-46.3$ & 0.2 & 48 & 41,1 & $37.9-45.6$ & 0.3 & 33 & 5.30 & $<0.001$ \\
\hline Claw 3 & 22.6 & $18.8-27.0$ & 0.2 & 50 & 20.5 & $16.0-25.6$ & 0.3 & 33 & 5.25 & $<0.001$ \\
\hline Body length & 311 & $255-356$ & 2.5 & 49 & 292 & $250-325$ & 3.1 & 31 & 4.75 & $<0.001$ \\
\hline Bill height & 21.6 & $19.6-24.8$ & 0.2 & 47 & 20.6 & $18.4-23.2$ & 0.2 & 31 & 4.00 & $<0.001$ \\
\hline Tail & 307 & $272-328$ & 1.6 & 47 & 292 & 194-315 & 3.9 & 28 & 3.59 & $<0.001$ \\
\hline Tarsus & 63.9 & $49.5-76.2$ & 0.7 & 48 & 60.3 & $44.0-69.7$ & 0.8 & 30 & 3.18 & 0.002 \\
\hline
\end{tabular}


Table 2. The three top models, based on AIC model selection, for determining sex of the Great Grey Owl by logistic regression modelling, with statistically significant parameters shown in bold.

\begin{tabular}{lllllll}
\hline Intercept & Age & Weight & Wing & Forearm & $2^{\text {nd }}$ claw & AIC \\
\hline & & & & & & \\
$\mathbf{- 2 1 2 . 0 0 0}$ & 2.412 & 0.005 & $\mathbf{0 . 2 6 1}$ & $\mathbf{0 . 4 5 3}$ & $\mathbf{0 . 9 0 2}$ & 31.653 \\
$\mathbf{- 2 0 5 . 9 2 3}$ & 2.299 & & $\mathbf{0 . 2 5 6}$ & $\mathbf{0 . 4 0 3}$ & $\mathbf{1 . 2 1 9}$ & 31.381 \\
$\mathbf{- 1 6 7 . 4 4 7}$ & & & $\mathbf{0 . 1 9 8}$ & $\mathbf{0 . 3 8 3}$ & $\mathbf{0 . 9 7 4}$ & 32.713 \\
\hline
\end{tabular}

CI 0.858-0.991; Figure 1). Reason for this discrepancy may lie in high variance of the weight (CV 37\% for females and $32 \%$ for males) that disturbs the ROCestimation. High variance in weight is due to both starved and well-conditioned individuals in the sample when females can sometimes be lighter than males. For forearm alone the accuracy was $91.7 \%(\mathrm{CI}=0.849$ 0.985 , Figure 1). Best model based on AIC included also age of birds (juvenile/adult classification). Juvenile birds were generally smaller than adults, especially among the males. Claws were $1 \mathrm{~mm}$ shorter in juvenile than in adult males, on average, while in females there were practically no differences between the age classes.

Among the 76 owls, the males' forearm ranged 123$148 \mathrm{~mm}$, and was on average $138 \mathrm{~mm}(\mathrm{n}=31)$, while the forearm of females ranged 131-162 mm, and was on average $147 \mathrm{~mm}(\mathrm{n}=49)$. Forearm measurements had far less overlap than wing length measurements. Only 18 out of 80 specimens $(17.5 \%)$ were placed in the overlap zone for forearm measurements, while the corresponding figure was $38.5 \%$ for wing measurements. Hence, forearm length even alone seems to be a fairly promising single measurement for reliability of sex determination in Great Grey Owls. By applying discriminant function analysis, where 13 measurements of 50 Eagle Owl skins were taken, Delgado and Penteriani (2004) could verify the superiority of forearm length over the wing and tail lengths as a measure to determine sex. Balbontin et al. (2001) have also shown forearm length to be the best sex predictor for the Booted Eagle Hieraaetus pennatus. Ecological and evolutionary significance to explain higher Reversed Sexual Dimorphism (RSD) in forearm rather than wing length is not clear, but could have some connection with the heavier prey and mass of females requiring stronger bone structure in the wings rather than longer feathers (Mikkola \& Tornberg 2014, 2015). Since owl and hawk females have higher wing load than males, a relatively stronger pressure focuses on this part of the wing when flying (Sunde et al. 2003).
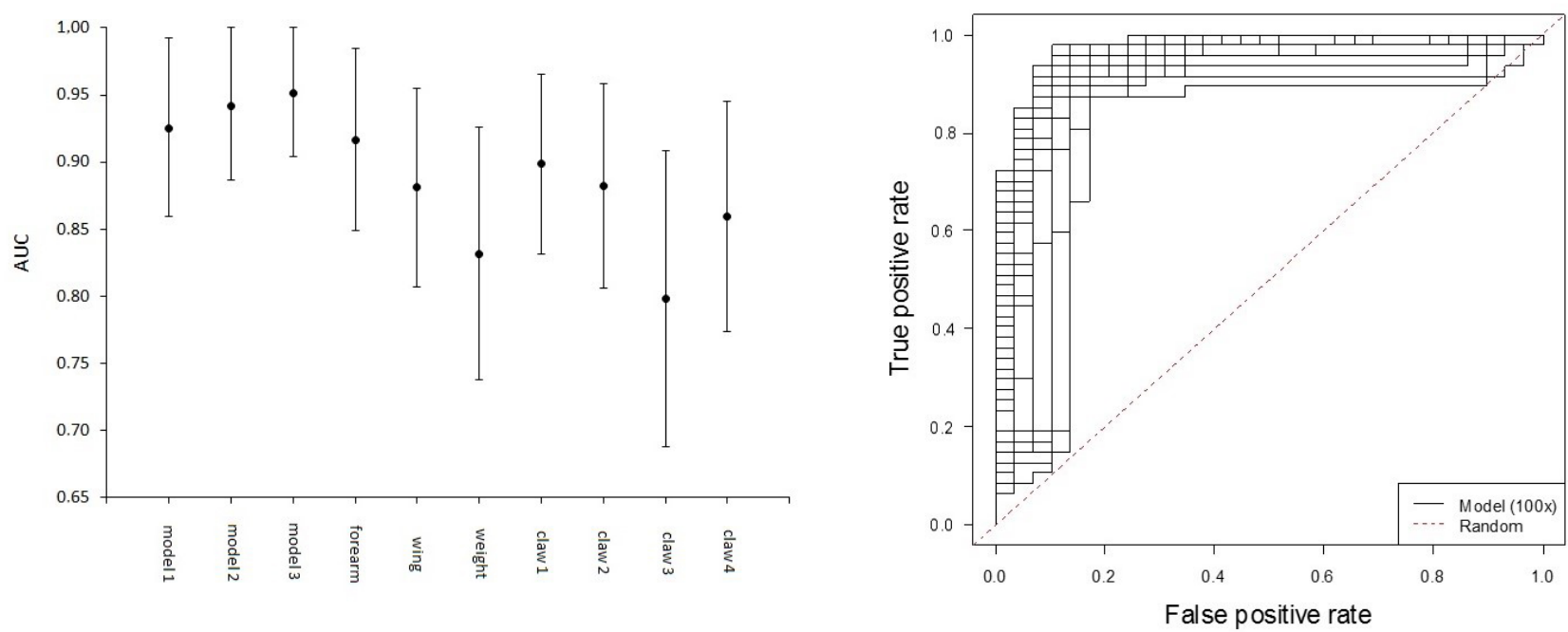

Figure1. ROC-curve estimates for the three best models for determining sex of the Great Grey Owl, based on measurements of wing length, weight, and forearm and four claw lengths of 76 specimens collected in western and northern Finland 1962-2004. Vertical bars denote $95 \%$ confidence limits of the ROC-estimate (left panel). ROC-curve formed by true-positive vs false-positive pairs shown in xy-coordinate diagram. Area under curve (AUC) depicts the accuracy of a specific model in predicting the sex correctly (right panel). Graph shows true positive-false positive pairs of 100 simulations and all possible paths that can be drawn via these pairs. Average of the curves limiting the space (AUC) between random results (dotted line) gives the value of the sex discrimination accuracy $(95 \%)$. 
Interestingly, according to our measurements, length of ulna does not show greater sexual dimorphism than any other character. Therefore, relatively longer forearm in females must depend on the size of carpal joint. A special bone os prominens exists in wings of Strigidae and Accipitridae mediating pulling force to forearm when spreading the wing (Bock \& McEvey 1969). It may be one reason for relatively longer forearm in females.

In addition to forearm length, another set of good predictors for sexing the Great Grey Owl was length of claws. We found the second claw to be the best, though the first claw (hallux) separated sex better in pairwise comparisons (Table 1). This is reasonable, because Mikkola and Tornberg (2015) found a sexual difference in the diet composition of the Great Grey Owls, with females being capable of killing larger prey than males. Birds of prey mostly subdue their prey by piercing them with their sharp claws. Delgado and Penteriani (2004) found similarly the second claw to be the best sex predictor of the European Eagle Owl, but tarsus length, culmen, and bill depth performed equally well in their data. Length of claws may also be applicable to other owls. Sunde et al. (2003) found that among body measures taken from Tawny Owls (Strix aluco), RSD was largest for the diameter of the hind claw. Similarly, Rantamäki and Aaltonen (2015) using a larger material found no overlap in the fourth claw measurements between the sexes in live-trapped Tawny Owls during the breeding season. The hind toe claw was below $16 \mathrm{~mm}(\mathrm{n}=28)$ in males, while that of females was over $16 \mathrm{~mm}(\mathrm{n}=28)$. Length of the hind claw has been found to separate sex also in Ural Owls (Strix uralensis) it being in males $17.7 \mathrm{~mm}(\mathrm{n}=18)$ and in females $20.7 \mathrm{~mm}(\mathrm{n}=20)$, on average (Kivelä (2009). Surprisingly, statistically not so clear difference was found for closely related Great Grey Owl. Smaller prey size in this species could at least partly explain this difference within the Strix species (Mikkola \&Tornberg 2015).

Poor performance of tarsus in determining sex in our data, contrary to findings by Delgado \& Penteriani (2004), may derive from inaccuracies in measuring tarsus during museum preparations, since coefficient of variation for this measurement was fairly high; 7.6$8.0 \%$ compared to $2.9-3.7 \%$ for wing measurements. Bill depth was in many cases difficult to measure in skins where bill was dried partly open.

In the museum collections there may be some false sexing, particularly in the case of first year birds in autumn, when most dead owls are found (see Mikkola \& Tornberg 2014). During that time of the year temperatures are still well above freezing, so birds easily decay, especially around the intestines where the genitals are situated. Yet, there were exceptional "oversized" males and too small females, which were reliably sexed. Such individuals may have faced ample or restricted nutrition during chick and fledging periods (Monaghan 2008). As a small mammal specialist, the Great Grey Owl faces abundance of food during peak vole years (Mikkola 1981, Sulkava \& Huhtala 1997) and paucity of food during poor vole years, the latter very often leading to starvation (Mikkola et al. 2013). In spite of this unavoidable overlapping between sexes in the measurements, forearm and claw length measurements seem very promising as the best field method in sexing live Great Grey Owls when ringing outside the breeding season.

Acknowledgement. The authors would like to thank Geir A. Sonerud for all his helpful suggestions with the manuscript.

\section{REFERENCES}

Balbontin, J., Ferrer, M. \& Casado, F. 2001. Sex determination in Booted Eagle (Hieraeetus pennatus) using molecular procedures and discrimination function analysis. Journal of Raptor Research 35: 20-23.

Berg, T. 2010. Lappuglene kommer. Vår Fuglefauna 33: 112117. (In Norwegian)

Bock, W.J. \& McEvey, A. 1969. The radius and the relationships of owls. Wilson Bulletin 81: 55-68.

Burnham, K.P. \& Anderson D.R. 2002. Model selection and multimodel inference: a practical information - theoretic approach. Springer, New York.

Delgado, M. \& Penteriani, V. 2004. Gender determination of European Eagle-owls (Bubo bubo) by morphology. Journal of Raptor Research 38: 375-377.

Kivelä, J. 2009. Viirupöllöemojen pyyntiä 2008 ja koiraspyynnin tuloksia 2008-2009. Satakunnan linnut 41(3): 8-14. (In Finnish)

Ławicki, Ł., Abramčuk, A.V., Domashevsky, S.V., Paal, U., Solheim, R., Chodkiewicz, T. \& Woźniak, B. 2013. Range extension of Great Grey Owl in Europe. Dutch Birding 35: 145-154.

Martínez, J.A., Zuberogoitia. Í. \& Alonso, R. 2002. Rapaces Nocturnas. Guía para la determinación de la edad y el sexo en las estrigiformes ibéricas. Monticola Ediciones, Madrid. (In Spanish)

Mikkola, H. 1981. Der Bartkauz Strix nebulosa. Die Neue Brehm-Bücherei 538. Ziemsen, Wittenberg Lutherstadt. (In German)

Mikkola, H. 2013. Owls of the World. A photographic guide. 2nd Edition. Christopher Helm, London.

Mikkola, H. \& Lamminmäki, J. 2014. Suomen pöllöjen sulkasadon. iän ja sukupuolen määritysopas. (Moult, ageing and sexing of Finnish Owls). Suomenselän Lintumiehet ry. Saarijärvi. (In Finnish and English)

Mikkola, H. \& Tornberg, R. 2014. Sex-specific diet analysis of the Eurasian Eagle Owl in Finland. Ornis Fennica 91: 195-200.

Mikkola, H. \& Tornberg, R. 2015. Sex-related dietary differences in three Strix-species in North Eurasia. Pp. 
570-571 in: Kovshar, A.F. (ed.). XIV International Ornithological Conference of Northern Eurasia, I. Abstracts. Almaty 18-24 August 2015, Kazakhstan.

Mikkola, H., Tornberg, R. \& Willard, D.E. 2013. Sex-related dietary differences in Great Gray Owls in Finland and the USA. Ontario Birds 31: 161-171.

Monaghan, P. 2008. Early growth conditions, phenotypic development and environmental change. Philosophical Transactions of the Royal Society, B 363: 1635-1645.

Nero, R. 1980. The Great Gray Owl: phantom of the northern forest. Smithsonian Institution Press, Washington D.C.

Press, S.J. \& Wilson, S. 1978. Choosing between logistic regression and discriminant analysis. Journal of the American Statistical Association 73: 699-705.

Rantamäki, A. \& Aaltonen, E. 2015. Sexing of Tawny Owls in field measurements. Satakunnan linnut 47: 45-47. (In Finnish with English summary)

Robin, X., Turck, N., Hainard, A., Tiberti, N., Lisacek, F., Sanchez, J-C. \& Müller, M. 2015. pROC. R Package. Version 1.8. Available at: http://cran.r-project.org/
web/packages/pROC/pROC.pdf

Sokal, R.R. \& Rohlf, F.J. 1995. Biometry, the principles and practice of statistics in biological research. W.H. Freeman \& CO, New York.

Solheim, R. 2009. Lappugla - en klimaflyktning på vei sydover? Vår Fuglefauna 32: 164-169. (In Norwegian)

Stefansson, O. 1997. Lappugglan (Strix nebulosa lapponica) Nordanskogens vagabond. Ord \& visor förlag. Skellefteå. (In Swedish and English)

Sunde, P., Bølstad, M.S. \& Møller, J.D. 2003. Reversed sexual dimorphism in Tawny Owls, Strix aluco, correlates with duty division in breeding effort. Oikos 101: 265-278.

Sulkava, S. \& Huhtala, K. 1997: The Great Gray Owl (Strix nebulosa) in the changing forest environment of Northern Europe. Journal of Raptor Research 31: 151-159.

Suopajärvi, P. \& Suopajärvi, M. 1994. Lapinpöllön iän määrittäminen. Linnut 29: 27-30. (In Finnish)

Received 18 January 2016. Accepted 7 April 2016 